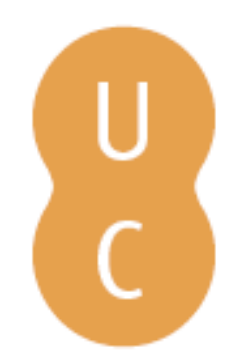

\title{
pommalina
}

\section{O Estado unitário, o federalismo e o regionalismo}

Autor(es): $\quad$ Silva, Maria Manuela Magalhães; Alves, Dora Resende

Publicado por: Imprensa da Universidade de Coimbra

URL

persistente:

URI:http://hdl.handle.net/10316.2/47432

DOI:

DOI:https://doi.org/10.14195/978-989-26-1524-0_8

Accessed : $\quad$ 26-Apr-2023 11:31:24

A navegação consulta e descarregamento dos títulos inseridos nas Bibliotecas Digitais UC Digitalis, UC Pombalina e UC Impactum, pressupõem a aceitação plena e sem reservas dos Termos e Condições de Uso destas Bibliotecas Digitais, disponíveis em https://digitalis.uc.pt/pt-pt/termos.

Conforme exposto nos referidos Termos e Condições de Uso, o descarregamento de títulos de acesso restrito requer uma licença válida de autorização devendo o utilizador aceder ao(s) documento(s) a partir de um endereço de IP da instituição detentora da supramencionada licença.

Ao utilizador é apenas permitido o descarregamento para uso pessoal, pelo que o emprego do(s) título(s) descarregado(s) para outro fim, designadamente comercial, carece de autorização do respetivo autor ou editor da obra.

Na medida em que todas as obras da UC Digitalis se encontram protegidas pelo Código do Direito de Autor e Direitos Conexos e demais legislação aplicável, toda a cópia, parcial ou total, deste documento, nos casos em que é legalmente admitida, deverá conter ou fazer-se acompanhar por este aviso. 
JOSÉ MANUEL PUREZA JOSÉ JUSTE RUIZ (COORDS.)
IMPRENSA DA

UNIVERSIDADE

DE COIMBRA

COIMBRA

UNIVERSITY

PRESS
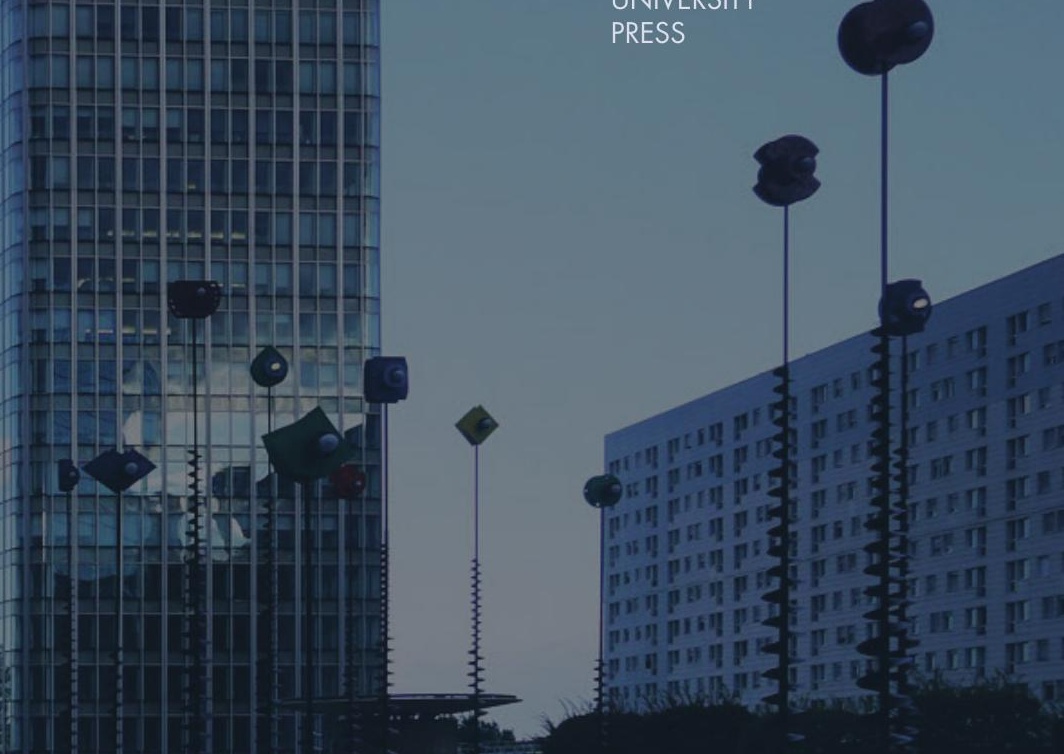

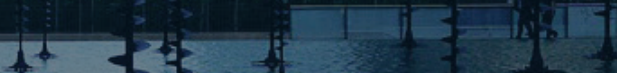

OS ESTADOS

EA ORDEM

INTERNACIONAL

CONTEMPORANEA

ATAS DO V ENCONTRO LUSO-ESPANHOL DE Professores de Direito internacional e RELAÇÕES INTERNACIONAIS 


\title{
O ESTADO UNITÁRIO, O FEDERALISMO E R E G I O N A L I S M O
}

\author{
Maria Manuela Magalhães Silva \\ Dora Resende Alves
}

\section{Introdução}

Tendo em conta o tema sobre a heterogeneidade dos Estados e a ordem internacional contemporânea, as formas de Estado revela-se uma matéria atinente. A estrutura territorial do poder surge em diferentes modelos estatais, tais como o Estado unitário regional e o Estado Federal, o que conduz à necessidade de verificação de eventuais características comuns, numa proposta de investigação comparada entre modelos historicamente próximos.

$\mathrm{Na}$ investigação proposta, surge o sistema unitário português, submetido à comparação com a realidade constitucional espanhola e com uma análise da organização territorial brasileira e sua disposição constitucional, para debater os elementos gerais das suas fórmulas constitucionais de organização territorial de poder.

No primeiro momento, é realizada menção geral a respeito das formas de Estado para possibilitar a visualização das diferenças estruturais envolvendo os Estados Unitários ou Simples dos Estados Descentralizados ou compostos. 
Estabelece-se uma ligação entre o Estado português e o Estado espanhol, pela proximidade territorial, e ainda o Estado brasileiro, pela proximidade histórica.

A conclusão procura unir os pontos apresentados para refletir sobre a categorização do modelo de Estado Unitário português.

\section{Forma de Estado}

As condicionantes que tornam cada Estado único são múltiplas e da mais diversa ordem: geográfica, histórica, linguística, racial, religiosa, económica, política,... Não chega já, portanto, o conceito clássico da organização do Estado, constante desde o século XVIII, com os seus três elementos estruturais. A verificação dos seus elementos tradicionais - povo, território e poder político - revelase hoje não suficiente para o caracterizarmos, se bem que continue um ponto de partida importante e ainda quase sempre referenciado. Mas, de entre outras abordagens, é daqueles chamados elementos estruturais do Estado que assim se chega à compreensão do conceito de forma de Estado, que procura traduzir a estruturação interna do poder estadual e do ordenamento jurídico constitucional que rege determinada coletividade (Silva e Alves, 2010: 329), no sentido de encontrar o ou os diversos centros de poder. Isto é, traduz-se no modo de organização dos centros de produção das suas normas jurídicas e respectivos ângulos espaciais de validade, constatando-se, aí, ou não, diversos níveis de governo na intensidade das suas actuações.

Resulta que os critérios de distinção têm a ver com o seguinte: saber se num determinado Estado existe apenas um poder ou vários conjuntos de autoridade e instituições de governo; se existe apenas um centro de decisão política ou vários centros de decisão; e se existe só uma constituição ou a integração de vários ordenamentos jurídico-constitucionais. 


\section{O Estado unitário regional e o Estado federal}

Tendo por base os critérios enunciados para distinguir formas de Estado, a divisão fundamental na doutrina é feita entre Estado simples e Estado composto

Dentro do Estado simples, surge um único tipo que é o Estado unitário. No Estado unitário, temos uma só constituição, órgãos de soberania únicos para todo o território nacional, uma única ordem jurídica. Contudo, comporta a possibilidade de diferenciação de territórios com autonomia. Caracteriza-se pela existência de um único conjunto de autoridade ou instituição de governo; um só centro de decisão política e um único ordenamento jurídico-constitucional para todo o território. Toda a actividade relacionada com o poder político estadual passa por uma entidade central que controla na totalidade o funcionamento do Estado. O que importa no Estado unitário ou simples é que as descentralizações possíveis de ocorrerem não possuem força suficiente para questionar a estrutura determinada pelos actos do governo central, de maneira que a visualização da estrutura de poder se apresenta de uma forma homogénea e com apenas um nível.

Como exemplo de Estado unitário regional, e que nos interessa no presente artigo, surge o Estado português, no qual como pressupostos da descentralização administrativa se reconhece a autonomia não somente administrativa e financeira a apenas duas entidades territoriais, de acordo com o artigo $6 .^{\circ}$ da Constituição da República Portuguesa (CRP) que estabelece o respeito pelo regime de autonomia insular e os princípios da subsidiariedade, da autonomia das autarquias locais e da descentralização democrática da administração pública como bases estruturantes do modelo estatal. Neste caso, parcial, porque abrange apenas os territórios insulares, no caso de Espanha, que veremos também, todo o território nacional. 
Temos, então, o princípio da unidade do Estado no artigo 6. ${ }^{\circ},{ }^{\circ}{ }^{\circ}$ 1, da CRP, com um só texto constitucional. As Regiões Autónomas são dotadas de um documento próprio, o Estatuto político-administrativo (artigo $226 .^{\circ}$ da CRP), que define o modo de funcionamento regional, mas sempre respeitando a Constituição única e aprovado pela órgão legislativo com primado que é a Assembleia da República (artigo 161. ${ }^{\circ}$, alínea c), da CRP). Refere o mesmo número do mencionado artigo $6 .^{\circ}$ da CRP, o princípio da subsidiariedade, ligado ao funcionamento do Estado unitário com uma estruturação plural do território (artigos $225 .^{\circ}$, n. $^{\circ} 2$, e $235 .^{\circ}$, n. ${ }^{\circ} 2$, da CRP) ${ }^{1}$. No artigo, fala-se de um princípio de autonomia local, ligado às autarquias locais (artigo 242. ${ }^{\circ}$ da CRP). Também, da autonomia insular cujo regime jurídico-constitucional compreende autonomia normativa, legislativa e regulamentar, administrativa, económica e financeira e decisória (Canotilho e Moreira, 2007: 233). O princípio da descentralização administrativa adquire diversos sentidos. A existência de Regiões Autónomas constitui uma descentralização política, diferente da descentralização administrativa do Estado (Canotilho e Moreira, 2007: 235), essa prevista no artigo $267 .^{\circ}$ da CRP.

Também, como outro caso de Estado unitário regional, o exemplo da Espanha, aí com todo o território dividido em comunidades autónomas. Eventualmente, nem todas com iguais poderes e autonomia.

Nos Estados compostos é que temos já vários tipos possíveis como a união real, que pode ser sob a forma de união pessoal, o Estado confederado ou confederação e o Estado federal ou federação. São possíveis vários textos constitucionais. É a este último que nos vamos também reportar.

${ }^{1}$ Embora se volte a falar deste princípio com um diferente sentido a propósito do direito da União Europeia, que também o consagra. Ver o artigo $7 .^{\circ}$, n. $^{\circ} 6$, da CRP (Canotilho e Moreira, 2007: 233). 
Nos Estados compostos são encontrados distintos níveis de produção de poder, entidades responsáveis pela produção de normas jurídicas com âmbito de validade restritas a dimensões territoriais predeterminadas, que podem ser de extensão nacional, regional ou até local. Eles possuem vários centros de decisão, várias instituições de governo e a integração de vários ordenamentos jurídico-constitucionais. A coexistência de diversas fontes de produção de poder no território do Estado composto faz com que o modelo de descentralização tenha que ser respeitado de acordo com o definido pela Constituição central, não sendo possível imprimir modificações unilaterais nas esferas de atribuição e competência das entidades territoriais. Aqui, a organização dos centros de poder manifesta-se de forma heterogénea, apresentando dois ou mais níveis na sua estrutura. Entre as formas possíveis vamos destacar o caso do Estado federal do Brasil e o federalismo brasileiro.

O Estado composto federal é formado por Estados federados, com poder político em nome próprio, embora de âmbito não internacional, porque dependentes do Estado federal e sua Constituição. Contudo, detêm, eles próprios, uma Constituição.

Note-se que a representação internacional do Estado cabe sempre ao Estado soberano.

\section{Portugal, Espanha e Brasil}

Por ser a nossa realidade e realidades próximas de nós, um país por partilhar como nosso único vizinho $1215 \mathrm{~km}$ de fronteira e toda a história desde o século XII, outro porque fez parte da estrutura do Reino de Portugal, e por se relacionarem com o âmbito deste Encontro, a análise reporta-se com maior pormenor ao que 
refere a Constituição portuguesa ${ }^{2}$, a Constituição espanhola ${ }^{3}$ e a Constituição brasileira ${ }^{4}$.

Na República Portuguesa ${ }^{5}$, a Constituição portuguesa atual, com 39 anos de vigência, tem, conforme é comum a muitas constituições, um capítulo introdutório com os Princípios Fundamentais que regem o texto constitucional. E aí, regras relativas à caracterização do Estado (artigo $2 .^{\circ}$ da CRP), à cidadania (artigo $4 .^{\circ}$ da CRP) e, precisamente, ao território nacional (artigos $5 .^{\circ}$ e $6 .^{\circ}$ da CRP) ${ }^{6}$. Aí identifica o território português, com as fronteiras mais antigas

${ }^{2}$ A Constituição da República Portuguesa de 2 de Abril de 1976, na redacção que lhe foi dada pelas sete revisões constitucionais: Lei Constitucional $n .^{\circ} 1 / 82$ de 30 de Setembro (DR n. ${ }^{\circ}$ 227); Lei Constitucional $n .^{\circ} 1 / 89$ de 8 de Julho; Lei Constitucional n. ${ }^{\circ} 1 / 92$ de 25 de Novembro; Lei Constitucional $n .^{\circ} 1 / 97$ de 20 de Setembro; Lei Constitucional n. ${ }^{\circ} 1 / 2001$ de 12 de Dezembro (DR n. ${ }^{\circ} 286$, p. 8172); Lei Constitucional n. ${ }^{\circ} 1 / 2004$ de 24 de Julho (DR n. ${ }^{\circ}$ 173, p. 4642) e Lei Constitucional n. ${ }^{\circ}$ 1/2005 de 12 de Agosto (DR n. ${ }^{\circ}$ 155, p. 4642).

É o sexto texto fundamental português. Antes: a Constituição de 23 de Setembro de 1822; a Carta Constitucional de 29 de Abril de 1826; a Constituição de 4 de Abril de 1838; Constituição de 21 de Agosto de 1911; e a Constituição de 11 de Abril de 1933.

3 A Constituição Espanhola de 29 de dezembro de 1978, com a última modificação de 27 de setembro de 2011. Depois de: Carta de Bayona de 1808, a Constituição de Cádiz de 19 de Março de 1812; o Estatuto Real de 10 de Abril de 1834; a Constituição de 18 de Junho de 1837; a Constituição de 23 de Maio de 1845; a Constituição de 1 de Junho de 1869; a Constituição de 30 de Junho de 1876; a Constituição de 9 de Dezembro de 1931; e as Leis Fundamentais do Franquismo.

${ }^{4}$ O texto da Constituição Brasileira atual, de 5 de Outubro de 1988, com os seus 86 aditamentos até Março de 2015, pode ser consultado em http://www. planalto.gov.br/ccivil_03/constituicao/constituicaocompilado.htm. Esta é a sétima Constituição brasileira, a saber: a Constituição Política do Império do Brasil de 25/03/1824; Constituição da República dos Estados Unidos do Brasil de 24/02/1891; Constituição da República dos Estados Unidos do Brasil de 16/07/1934; Constituição dos Estados Unidos do Brasil de 10/11/1937; Constituição dos Estados Unidos do Brasil de 18/09/1946; Constituição do Brasil de 24/01/1967; Constituição do Brasil de 24/01/1967, com a redação de 17/10/1969.

5 Segundo os dados válidos para 2015, para a União Europeia, com uma população de 10.427.301.000, pela Decisão do Conselho 2014/900/UE. Num território de cerca de $92.212 \mathrm{~km}^{2}$.

${ }^{6}$ Muito útil nesta matéria a intervenção O Garantismo Constitucional. Constituição Penal. apresentada pela Professora Maria Manuela Magalhães Silva nas II Jornadas Luso-Brasileiras sobre Garantismo Constitucional - Penal, que decorreram no dia 31 de Julho de 2014, em Coimbra. 
da Europa ${ }^{7}$, como simultaneamente continental e insular, com um "território historicamente definido" na Península Ibérica, no continente europeu, e ilhas com "os arquipélagos dos Açores e da Madeira".

O Estado português é portanto regional mas apenas na vertente insular dos Açores e da Madeira, não podendo surgir outras regiões autónomas no seu território. Os poderes das regiões autónomas não são originários e derivam da Constituição do Estado.

A consagração das regiões autónomas portuguesas, não sendo original (Canotilho e Moreira, 2007: 236) ${ }^{8}$, constituiu uma das grandes inovações da CRP (Canotilho e Moreira, 2007: 235) que não põe em causa a unidade do Estado (artigo 225..$^{\circ}$ n. ${ }^{\circ} 3$, da CRP). São dotadas de autonomia legislativa e governamental (artigos $227 .{ }^{\circ}$ da CRP), com órgãos legislativos (Assembleias Legislativas das Regiões Autónomas, artigo 232..$^{\circ}$ da CRP) e políticos próprios (Governo e Representante da República, artigos $225 .^{\circ}$ e $231 .^{\circ}$ da CRP). Também com uma autonomia económica e financeira (artigos $164 .^{\circ}$, alínea t), e $229 .^{\circ}$, n. $^{\circ}$ 3, da CRP) (Canotilho e Moreira, 2007: 235). Não podem, contudo, estabelecer o seu próprio estatuto, embora participem na sua elaboração, com a categoria de lei ordinária de valor reforçado e alcance geral (artigo 226..$^{\circ}$ da CRP), o que afinal teria que acontecer atento o interesse regional (artigo 228. ${ }^{\circ}, \mathrm{n} .^{\circ} 1$, da CRP).

O Reino da Espanha 9 ocupa cerca de $90 \%$ do território da Península Ibérica e inclui os arquipélagos das Canárias e das Baleares

7 Remontam, com poucas alterações ao século XIII, em 1279 no fim do reinado de D. Afonso III (1248-1279), consolidadas no reinado de D. Dinis (1279-1325) com a celebração do Tratado de Alcanices com D. Afonso $X$, de Castela, em 12 de Setembro de 1297.

8 Precedente na Constituição Política da República Portuguesa de 11 de Abril de 1933, na Lei de revisão constitucional n. ${ }^{\circ} 3$ de 16 de Agosto de 1971 ou as já então previstas comunidades autónomas espanholas da Constituição da II República Espanhola.

9 Segundo os dados válidos para 2015, para a União Europeia, com uma população de 46.507.760.000, num território de cerca de $504.030 \mathrm{~km}^{2}$, o segundo maior território da Europa ocidental. Território construído a par da reconquista cristã desde 
e pequenas ilhas próximo de Marrocos. Este país foi bem cedo dotado de um texto constitucional (Gouveia, 2011: 394), consagra hoje a organização territorial do Estado no Título VIII, no artigo $137 .^{\circ}$ com todo o seu território organizado em municípios, províncias e em Comunidades Autónomas (17 comunidades autónomas, divididas em 50 províncias, e duas cidades autónomas - Ceuta e Melilla), se bem que afirme a unidade do Estado (artigo $2 .^{\circ}$ da Constituição espanhola). Estabelece competências que as comunidades autónomas podem assumir e outras exclusivamente atribuídas ao Estado (artigos $148 .^{\circ}$ e $149 .^{\circ}$ da Constituição espanhola) e que não são rigorosamente iguais entre si, variando o regime de autonomia conforme o respectivo Estatuto de Autonomia. Ainda, que com diferenças, os Estatutos das diferentes Comunidades Autónomas não poderão implicar privilégios económicos ou sociais (artigo $138 .^{\circ}, \mathrm{n} .^{\circ} 2$, da Constituição espanhola) e todos os espanhóis têm os mesmo direitos e obrigações em qualquer parte do território do Estado (artigo 139. ${ }^{\circ}$ da Constituição espanhola). Expressamente se sublinha a não equiparação entre as Comunidades Autónomas e estados federados (artigo $1455^{\circ},{ }^{\circ}{ }^{\circ} 1$, da Constituição espanhola).

A República Federativa do Brasil é o mais vasto país da América do Sul, de que ocupa cerca de $47 \%$ (o quinto maior país do mundo), hoje com 26 Estados federados e o Distrito Federal de Brasília ${ }^{10}$. Tornou-se uma República Federal com a sua Constituição de 1891. Em relação ao modelo federal brasileiro, o artigo $18 .^{\circ}$ da Constituição

o século XVIII e unificado através da união real de 1469 , com o casamento dos Reis Católicos, Fernando II de Aragão e Isabel I de Castela, que criou o Reino da Espanha.

10 Numa área de $8.515 .767 \mathrm{~km}^{2}$, com uma população de mais de 202 milhões de habitantes. O Brasil foi descoberto em 22 de Abril de 1500 por Pedro Álvares Cabral, no reinado de D. Manuel (1495-1521) e ficou como um território dependente de Portugal até à declaração de independência, embora passando à categoria de Reino em 1815 na regência de D. João VI (1816-1826). A Constituição Política da Monarquia Portuguesa de 23 de Setembro de 1822 ainda consagrou a União Real (artigo $20 .^{\circ}$ ), mas D. Pedro (1826) elevara-o a Império com a independência, logo em 7 de Setembro de 1822. 
Brasileira prevê a existência de quatro níveis distintos e autónomos de governo na sua estrutura, que compreendem: União Federal, Estados-Membros, Municípios (em número de 5.570) e Distrito Federal (segue-se Silva e Contipelli, 2015).

A União Federal representa o poder central, possuindo um extenso e importante rol de competências outorgadas pela Constituição brasileira, o que lhe atribui papel de maior relevância no cenário político nacional. Ressalte-se que a federação brasileira apresenta uma estrutura com elevado grau de centralização, tendo em vista que, diferentemente de outros modelos federativos, como os Estados Unidos da América, o processo de federalização brasileiro ocorreu por força de um movimento centrífugo, isto é, sua formação deriva, historicamente, da deslocação de poder do centro para as coletividades parciais (conversão das províncias componentes do Império em Estados-Membros, com o federalismo). No artigo $21 .^{\circ}$ da Constituição Brasileira estão previstas as competências exclusivas da União Federal, que consistem numa série de tarefas administrativas direcionadas à promoção de interesses federativos comuns. No artigo $22 .^{\circ}$, são elencadas as competências privativas legislativas, que podem ser objeto de delegação sendo conferidas para Estados-Membros e Distrito Federal, diferentemente das competências exclusivas que são marcadas pelo atributo de indelegabilidade.

\section{Níveis de Poder e Descentralização Constitucional}

Por sua vez, o sistema unitário português segue uma estruturação diferenciada no que diz respeito às unidades constitutivas insulares e continentais. $\mathrm{O}$ regime político-administrativo próprio dos arquipélagos de Açores e Madeira encontra um Título próprio na Constituição da República Portuguesa (Título VII), que confere a essas unidades constitutivas a condição de regiões autónomas, 
pelas suas características geográficas, económicas, sociais, culturais e nas históricas aspirações autonomistas das populações insulares, existindo inclusive um campo de competências legislativas próprias a essas territorialidades disposto no artigo $227 .^{\circ}$. No continente, o regime político-administrativo encontra-se disposto no Título VIII da Constituição Portuguesa, Poder Local, que compreende as autarquias locais, estas subdivididas em regiões administrativas, municípios e freguesias, conforme o artigo $236 .^{\circ}$. As constitucionalmente possíveis regiões administrativas nunca foram criadas (artigo $255^{\circ}$ da CRP) ${ }^{11}$.

Sendo certo que a representação internacional cabe ao Estado (artigo $7 .^{\circ}$ da CRP), as Regiões Autónomas serão ouvidas em matéria internacionais que lhes digam directamente respeito (artigo 227. , n. ${ }^{\circ}$, alíneas t) e v), da CRP) e, até, podem estabelecer cooperação directa com outras entidades estrangeiras (artigo 227. ${ }^{\circ},{ }^{\circ}{ }^{\circ} 1$, alíneas u) e x), da CRP).

A Espanha funciona como um dos países mais descentralizados da Europa, porque todos os seus diferentes territórios administram de forma local, por exemplo, os seus sistemas de saúde, educativos e de segurança (mencionado artigo $148 .^{\circ}$ da Constituição Espanhola), assim como as Comunidades Autónomas gozam de autonomia financeira (artigo $156 .^{\circ},{ }^{\circ}{ }^{\circ}$ 1, da Constituição Espanhola).

As Comunidades Autónomas, apesar da sua visibilidade internacional, não detêm qualquer representatividade na cena internacional, visto que essa cabe ao Estado (artigos $94 .^{\circ}$ e $149 .^{\circ}$, n. ${ }^{\circ} 1,3 .^{a}$, da Constituição Espanhola).

$\mathrm{Na}$ União Federal do Brasil (segue-se Silva, 2014), o artigo $21 .^{\circ}$ da Constituição Brasileira prevê as competências exclusivas da União Federal, que consistem numa série de tarefas administrativas direcionadas à promoção de interesses federativos comuns. No

11 A tentativa da sua criação deu lugar ao primeiro referendo português (previsto no artigo $115 .^{\circ}$ da CRP), em 1998 , que rejeitou a ideia. 
artigo 22..$^{\circ}$, estão previstas as competências privativas legislativas, as quais, conforme o parágrafo único deste dispositivo, podem ser objeto de delegação sendo conferidas para Estados-Membros e Distrito Federal, de modo diferente das competências exclusivas que são marcadas pelo atributo indelegabilidade.

Aos Estados federados, entidades representativas do âmbito de interesses regionais, a Constituição brasileira atribui um campo residual de competências (artigo $25 .^{\circ}$ ) que, por não se encontrar enumerado, deve ser identificado a partir das limitações explícitas e implícitas que lhe são impostas pelo próprio texto constitucional. Por exemplo, o Estado federado não poderá dispor, sem a devida autorização legal, sobre a matéria contida expressamente no âmbito de competências da União ou Municípios.

Para além disso, os Estados federados possuem as competências expressas no artigo $25 .^{\circ}$ da Constituição Brasileira (por exemplo, § $2 .^{\circ}$ ou $3 .^{\circ}$, que revelam a nítida opção do poder constituinte pela aplicação do princípio da predominância do interesse, como se vê na atribuição do tratamento de assuntos intermunicipais à autonomia dos Estados federados.

Os Municípios, com o advento da Constituição de 1988, foram definitivamente elevados ao patamar de entidade federativa, sendo dotados de todos os atributos pertinentes à autonomia política (organização, legislação, governo, administração e finanças próprias), possuindo competências exclusivas para tratamento de assuntos de interesse local, bem como suplementar para completar lacunas existentes nas legislações federais e estaduais em relação às suas particularidades. Tal situação acaba por colocar o modelo federativo brasileiro, adotado pela Constituição vigente, numa situação peculiar, em razão da inclusão e da extrema atenção conferida à figura do Município perante as demais unidades constitutivas da federação.

O campo de auto-legislação dos Municípios está determinado no $\operatorname{artigo~} 300^{\circ}$ da Constituição Brasileira, que lhe outorga competência 
legislativa exclusiva para tratar de assuntos de interesse local; e a competência suplementar para preencher as lacunas existentes na legislação federal e estadual, ajustando o conteúdo das matérias reguladas às suas particularidades.

O Distrito Federal, inspirado no sistema norte-americano, consiste num espaço territorial neutro, que tem como função albergar a sede do governo central, outorgando-lhe autonomia política para evitar possíveis interferências no local de decisões políticas pertinentes a toda federação. Assim, foram conferidas ao Distrito Federal as mesmas competências reservadas aos Estado federados e Municípios (artigo 32. ${ }^{\circ}$, $1 .^{\circ}$, da Constituição Brasileira), sendo que algumas matérias, tais como organização do poder judiciário, que estariam normalmente no campo de competência dos Estados federados, foram atribuídas à União (artigo 21. ${ }^{\circ}$, XIII e XIV, da Constituição Brasileira).

No que se refere ao sistema vertical de atribuição de competências, cite-se, inicialmente, o artigo $23 .^{\circ}$ da Constituição Brasileira, que determina o campo de competências comuns das unidades constitutivas, ou seja, partilhadas, em que a responsabilidade pela sua execução deve ser repartida entre todas as entidades federativas como forma de cooperação obrigatória.

Complementando o sistema de distribuição vertical, o artigo $24 .^{\circ}$ da Constituição Brasileira determina as competências legislativas concorrentes, que conferem à União Federal a tarefa de estabelecer as normas gerais sobre as matérias elencadas $\left(\S 1 .^{\circ}\right)$, reservando, assim, espaço para que Estados federados e Distrito Federal possam suplementar tais leis com a criação de normas específicas $\left(\S 2 .^{\circ}\right)$, que, logicamente, não poderão contrariar os termos das diretrizes genéricas contidas no plano federal.

Saliente-se que, no caso de inércia da União Federal no que se refere à edição de norma geral, Estados federados e Distrito Federal estão constitucionalmente autorizados a exercer compe- 
tência legislativa plena sobre a matéria com o fim de atender suas particularidades regionais no que seja estritamente necessário ( $\S$ $\left.3 .^{\circ}\right)$. Na hipótese de superveniência da norma geral federal sobre o assunto, será suspendida, no que se revelar contrária, a eficácia da lei estadual ou distrital $\left(\S 4 .^{\circ}\right)$.

Portanto, assim como os demais Estados que adotam a forma federal, o modelo brasileiro possui estrutura particularizada no que se refere à existência de distintos níveis de governo e a intensidade de poder outorgado a cada um deles, a qual se encontra adaptada à realidade jurídica e prática política vivida historicamente pelas suas instituições, o que se reflete na organização territorial de poder descrita no seu texto constitucional vigente e, sobretudo, na tendência à centralização excessiva do poder, com a atribuição de um amplo conjunto de competências politicamente estratégicas para o poder central, e na forte tradição municipalista, que revigora a figura de poder local.

Os Estados federados não gozam de representação nas relações internacionais do Estado federal, sendo esse o único com personalidade jurídica internacional (artigo 21. ${ }^{\circ}$, I, da Constituição Brasileira).

\section{Conclusão}

O sistema de organização estatal português apresenta uma estrutura ajustada a um modelo de Estado Unitário, sendo caracterizado, principalmente, no que respeita a presença de unidades constitutivas, pela existência de Regiões Autonómas insulares, Açores e Madeira, que não chegam a atribuir-lhe uma natureza composta, embora consagre um maior conteúdo de descentralização política para respeitar diversidade territorial de tais localidades.

Já o sistema espanhol de descentralização abarca todo o território do Estado, com variantes no grau de soberania adquirida historicamente e de forma gradual, ao longo do tempo. 
O sistema de descentralização de poder previsto pela Constituição Brasileira de 1988 ajusta-se a uma proposta federalista, enquadrando-se nas características comuns próprias deste modelo estatal. Apesar de certas particularidades que podem ser encontradas em qualquer nação, acabou por concentrar maiores poderes nas mãos da União Federal.

Em todos estes modelos, a representação internacional cabe exclusivamente ao Estado, num caso unitário noutro federal, embora se encontrem mecanismos diferenciados de audição das regiões com autonomia ou dos estados federados nos assuntos internacionais a ser deliberados.

\section{Referências}

CANOtilho, J. J. Gomes (2014), Direito Constitucional e Teoria da Constituição. Reimpressão da 7. ${ }^{a}$ Edição. Coimbra: Livraria Almedina.

; MOREIRA, Vital (2007) CRP Constituição da República Portuguesa Anotada. Volume 1. 4. ${ }^{a}$ edição. Coimbra Editora.

CONTIPELli, Ernani (2012), Federación y Estado Autonómico: Estudio de Derecho Constitucional Comparado Brasil - España. Granada: Editorial Comares.

GOUVEIA, Jorge Bacelar (2011), Manual de Direito Constitucional. 4. ${ }^{\mathrm{a}}$ ed. Coimbra: Almedina.

SILVA, Maria Manuela Magalhães (2014) O Garantismo Constitucional. Constituição Penal. Comunicação oral in II Jornadas Luso-Brasileiras sobre Garantismo Constitucional - Penal. 31 de Julho. Coimbra, ISBB - Instituto Superior Bissaya e Barreto.

; CONTIPELli, Ernani (2015), Federalismo e Estado Unitário: Comparações entre o Sistema Português e Brasileiro. Comunicação oral in I Congresso Jurídico de Investigadores Lusófonos. 13 de março. Porto, Faculdade de Direito da Universidade do Porto.

; ALVES, Dora Resende (2010), Noções de Direito Constitucional e Ciência Política. Reimpressão da 2. ${ }^{a}$ edição. Lisboa: Rei dos Livros. 